\title{
Modern Approach to the Procedures of Maintenance with Software Support and Its Application in Education
}

\author{
Branko Savić \\ Higher Education Technical \\ School, Novi Sad, Serbia
}

brsavic@yahoo.com

\author{
Bozo Ilic \\ Technical School Center, Zvornik, \\ Bosnia and Herzegovina
}

bozoilic66@gmail.com

\begin{abstract}
The area of maintenance has for long not been simple replacement of a part after its failure. The trend in maintenance today is to keep up with the development of computer technologies, which are increasingly being used. The education in the field of maintenance should also take this direction. This paper points to such an orientation, its goal being to point at the possibility of applying modern technologies, above all, information technologies, to the traditional areas, such as machine maintenance. The paper provides empirical data reflecting the chronology of modernizing the teaching methods in the subject Graphic Machinery and Maintenance.
\end{abstract}

Keywords: technical diagnostics, program, condition based maintenance.

\section{Introduction}

The area of maintenance has for long not been the replacement of a part after its failure. Maintenance has increasingly been the focus of attention in graphic industry, and the reason for that is the rapid technological development in the graphic machinery systems. This should be taken into consideration in the design of course syllabi in the area of maintenance. Another crucial factor is the tendency towards the increase in productivity and economy of production, which can only be achieved with regular maintenance of graphic systems at a high efficiency level. This can only be achieved if the employees on maintenance jobs are adequately trained for the work and if they can be directly included in the processes of production and maintenance (Bengtsson, 2002). The trends in maintenance are intensively following the development of computer technologies, which are being increasingly used. This direction should also be taken in education in courses related to maintenance. Certainly, continuous education of teachers is also necessary. The teacher has to be capable of assessing which new elements should be included in the syllabus, making the teaching material applicable in practice and demonstrating the application of skills and knowledge gained

Material published as part of this publication, either on-line or in print, is copyrighted by the Informing Science Institute. Permission to make digital or paper copy of part or all of these works for personal or classroom use is granted without fee provided that the copies are not made or distributed for profit or commercial advantage AND that copies 1) bear this notice in full and 2) give the full citation on the first page. It is permissible to abstract these works so long as credit is given. To copy in all other cases or to republish or to post on a server or to redistribute to lists requires specific permission and payment of a fee. Contact Publisher@InformingScience.org to request redistribution permission. during the course. That is also the main idea of this paper, whose goal is to point to potential applications of modern technologies, primarily in the traditional areas such as machinery maintenance. The paper contains empirical data, which show the chronology of modernizing the education in the field of graphic machines and maintenance. 
In the first part of the paper the author gives an overview of the technology of maintenance and its application in practice. As it is a very complex area, here are given only the basic terminology and notions related to the field of maintenance. Everything produced needs to be maintained, and this proves the importance of maintenance in all branches of industry. At this point, the paper deals with maintenance in graphic industry, but this study, with minor changes, can be applied to the fields of mechanical and electrical engineering and computer technology. This part of the paper shows what is important for students to learn in the field of maintenance, and where to apply this knowledge. As the field of maintenance is developing rapidly, and increasingly including elements of informational technologies, we believe that the teaching methodology should be adjusted to the development of technology. In this way the students are not going to be caught by surprise once they begin working with new technologies, but will be adequately prepared. Modernization of education in maintenance and the application of informational technologies are the focus of the second part of the paper. The following part illustrates the practical application of knowledge gained in the courses, i.e. it shows the active involvement of students in research work in companies, the analysis of results and taking adequate steps.

Generally, the paper points to what the student needs to learn in the subject of graphic machines maintenance. The knowledge of basic mathematical operations is assumed, as well as the elements of informational technologies, as necessary prerequisites for taking the course. In this way, once the student takes the course and passes the exam, he/she is ready to get involved in the production process and take active part in the area of maintenance.

\section{Traditional Education in Maintenance Subjects}

In times past, the importance of production efficiency and productivity did not gain as much attention, so that maintenance was mainly corrective, i.e. it was applied after a failure. This was the underlying principle in the designing of syllabi in the courses in maintenance. Following the costs of the functioning of systems revealed that the costs of maintenance were not low, but that they, depending on the industry type, ranged from 15 to $40 \%$ of production costs (Bengtsson, 2002). The attempts to reduce high costs of maintenance led to the emergence of preventive maintenance. The costs have been reduced, but since in preventive maintenance by replacing parts certain components of the system are regularly changed at particular time intervals, there remains the cost due to unused resources, as those parts could have worked for a longer period of time. This required a serious mathematical apparatus that could help calculate the time when the part is due to be replaced. After that, attention was also paid to the condition of the part to be replaced. Thanks to the development and application of devices for monitoring the condition of the parts and the development of mathematical models for finding the optimal moment for replacement and diagnostics, maintenance now mainly tends to be preventive and based on the condition of the parts. Condition based maintenance, or predictive maintenance, as it is also called, is based on the diagnostics of the condition of graphic systems, i.e. the systems of monitoring the condition of components. The highest level in maintenance is proactive maintenance, which builds on predictive maintenance, involves indispensable procedures of technical diagnostics. At these levels, however, serious problems are often encountered in the teaching process in the courses of maintenance, because the models are developed by mathematicians, who never apply them in maintenance practice, because they lack knowledge in the field. On the other hand, maintenance workers do not know mathematics well enough to be able to adjust the models and apply them in practice. Therefore, the education in these two subjects practically consisted of two unrelated segments. Of course, it should be strived to introduce modern maintenance concepts, such as predictive, or condition based maintenance.

Condition based maintenance is defined as maintenance carried out on the basis of comparing the required and measured parameters of the condition of the system, in this case the system of 
graphic machinery or its components (Bengtsson, 2002). That means that for a certain part, or a combination of parts, there are good, satisfactory and unsatisfactory parameters recommended for the operation of that part or system. By carrying out the procedures of technical diagnostics, the condition of a part is determined and compared to the recommended or required parameters, and on the basis of these results, the condition of the part or the system is determined. After that, if the value of the parameter measured is assessed as good, regular maintenance procedures are performed or, if they are not necessary, no steps are taken. If the parameter measured is satisfactory, the procedures of preventive maintenance are performed, and if the value of the parameter is unsatisfactory, the part has either failed or the failure is expected to take place.

There are numerous indicators of the condition of graphic machines, i.e. parameters which can be measured in order to establish the condition of a machine, or some of its components. The most commonly performed measurements are:

- vibration measurement,

- thermographic measurements (thermal scanning - measurement of temperature)

- tribological measurements (wear and tear, etc)

- measurements of processing parameters (operating parameters of the machine),

- ultrasound measurements (control without destruction),

- visual inspection, etc.

It is well worth mentioning that the development of preventive condition based maintenance brought to the development of new methods and models. Regarding the fact that technical diagnostics is used for determining the condition of the system, and that its performance requires modern and expensive equipment, as well as procedures of preparatory diagnostics, it can be assumed that this requires various expenses. In addition, unnecessary and frequent performance of diagnostics procedures interferes with the production process. Therefore, determining the moments at which to perform technical diagnostics is of crucial importance. This is the starting point for a whole new branch in the study of preventive condition based maintenance, where certain indicators determine the optimal moment of performing technical diagnostics. New models of condition based maintenance are developed, i.e. models for determining the optimal moment of carrying out technical diagnostics, or simply, the models of technical diagnostics. Their purpose is to determine the optimal time for performing condition diagnostics on the basis of indicators of reliability and maintenance costs (Powell, 2002).

\section{Modernizing the Subject}

Alongside the basic concepts and postulates of maintenance that the students learn in the course (corrective, preventive and combined), the curriculum has gone one step further in linking the gained knowledge with the practical application in graphic machinery. Indispensable part of any theory of maintenance is the knowledge of the models of technical diagnostics. In the literature there are several models of technical diagnostics (condition based maintenance), but there is little mention of their practical application, in contrast to the models of preventive maintenance by replacement of parts, such as Vhite's, Veisbaum's or Jorgenson's models (Baldin \& Furlaneto, 1980; Bengtsson, 2002). The reason is probably in the relatively recent date of emergence of the concept of preventive condition based maintenance, as well as the complexity of the models themselves. Another reason for infrequent application of the models of technical diagnostics is the fact that they are usually developed by mathematicians, who do not apply them in practice. However, it is only through the application of technical diagnostics that the exploitation level of graphic systems can be raised. As technical diagnostics is increasingly present in maintenance, 
we believe that a great deal of attention in teaching this subject should be given to technical diagnostics. This also implies the need to test the models in theory as well as in practice in the graphic industry on graphic machinery. Technical diagnostics studies various models of technical diagnostics, i.e. the methods of determining the optimal moment of diagnosing the state of the element observed. The diagnosed results determine whether the element should be replaced or further used in the system. In addition, they determine the time when the next diagnostic procedure of the elements should be carried out.

This led us to develop our own model, which would not only remain printed on paper, but would be applicable in practice and provide optimal and verifiable results. This model is included in the course syllabus in order to present a synthesis of outlining the problem, its solution and application in practice. The following part of the paper contains the development of the own model, its application and the development of a software program for the easier use of the own model.

\section{The Development of Our Model in the Maintenance Theory}

By studying various models of technical diagnostics and the application of those models in practice, the author has not encountered an appropriate combination of a model theory and its application (Baldin \& Furlaneto, 1980). As all of these models are significant for the field of maintenance and should therefore be studied, the author decided to develop his own model and apply it. Should it provide optimal results in practice, it can be considered appropriate and could be used in the teaching process.

The following images will help illustrate the proposition of a mathematical model (SAV-TT05B) for determining the optimal interval or moment of the diagnostics of the condition of the system or its components. Figure 1 is given below.

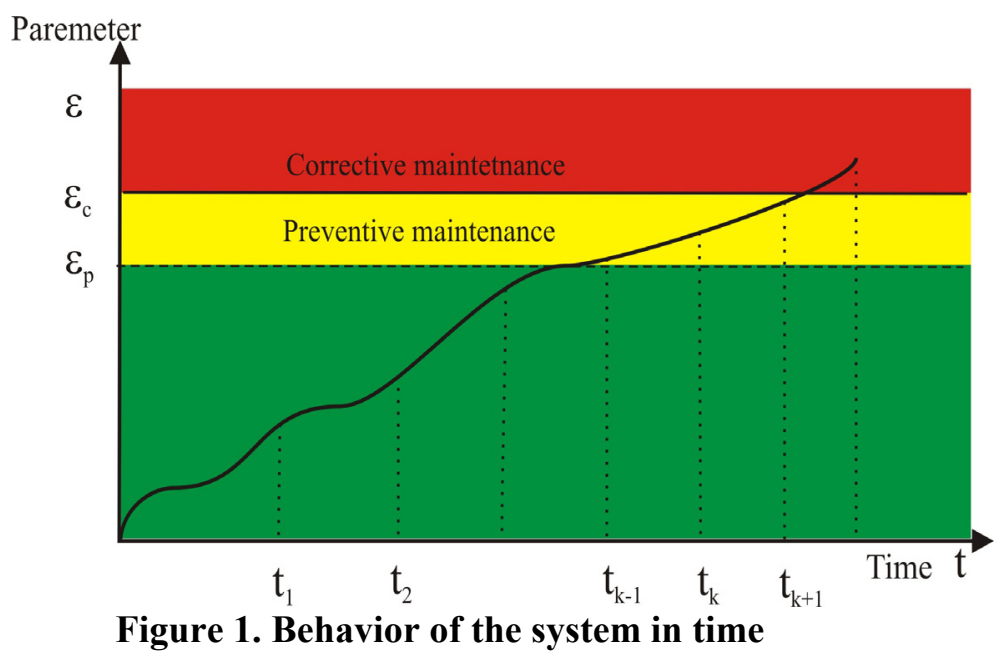

The graph (Figure 1) illustrates that the condition of the system or its components deteriorate over time, following a regular pattern. The deterioration of the system can be expressed through a measurable value, which is determined by performing technical diagnostics. This value is denoted by $\varepsilon$, and its conditions moves from the value $\varepsilon_{0}$, through $\varepsilon_{\mathrm{p}}$, which is the bottom level of carrying out preventive maintenance, to $\varepsilon_{\mathrm{c}}$, when it breaks down. The change in the system condition can be observed through various parameters, such as the raise in vibration rate, temperature, increase in wear and tear, tension, electricity consumption, etc. What is essential to do here is to correctly determine the limits of the wearing out. 
Based on the graph in Fig. 1, and by assuming the moments of technical diagnostics in Fig. 2, it is possible to propose a formula for calculating the overall maintenance costs.

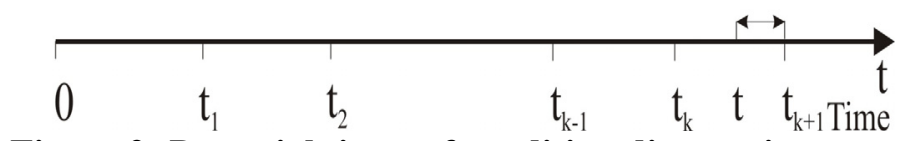

Figure 2: Potential times of condition diagnostics

The predicted times of technical diagnostics are marked as $t_{k}$ (Figure 1).

We assume that the overall costs are equal to (Savić, 2005):

$C_{u}=C_{i} P_{i}+C_{p} P_{p}+C_{c} P_{c}+C_{o} P_{o}$

We use the following values in the model:

$\mathrm{C}_{\mathrm{u}}$ - total cost of maintenance

$\mathrm{C}_{\mathrm{i}}-$ costs of performing technical diagnostics

$\mathrm{P}_{\mathrm{i}}$ - probability of diagnostics

$\mathrm{C}_{\mathrm{p}}$ - costs of preventive maintenance

$\mathrm{P}_{\mathrm{p}}$ - probability of preventive maintenance

$\mathrm{C}_{\mathrm{c}}-$ costs of corrective maintenance

$\mathrm{P}_{\mathrm{c}}$ - probability of failure

$\mathrm{C}_{\mathrm{o}}$ - costs due to failure

$\mathrm{P}_{\mathrm{o}}-$ probability of undiscovered failure

The probabilities of the occurrence of a condition, according to Figure 1 are equal to:

$P_{i}=\int_{0}^{\varepsilon_{c}} \varphi(\varepsilon) d \varepsilon \quad P_{p}=\int_{\varepsilon_{p}}^{\varepsilon_{c}} \varphi(\varepsilon) d \varepsilon \quad P_{c}=\int_{\varepsilon_{c}}^{\infty} \varphi(\varepsilon) d \varepsilon \quad P_{o}=\int_{\varepsilon_{c}}^{\infty} \varphi(\varepsilon) d \varepsilon$

In the formulae above $\varphi(\varepsilon)$ denotes the rate of change of the system condition.

The probability that inspection is going to take place, $\mathrm{P}_{\mathrm{i}}$, can be expressed as the function of system work without failure, i.e.:

$P_{i}=1-\int f(t) d t$, and the probability that corrective intervention will take place is equal to:

$P_{c}=\int f(t) d t$, where $f(t)$ is the function of density of system failures.

Applying the above formulae into the equation of total costs, on an infinite interval they become:

$C_{u}=\sum_{k=0}^{\infty}\left(\left(C_{i}(k+1)\left(1-\int_{t_{k}}^{t_{k+1}} f(t) d t\right)\right)+C_{c} \int_{t_{k}}^{t_{k+1}} f(t) d t+C_{o}\left(t_{k+1}-t\right) \int_{t_{k}}^{t_{k+1}} f(t) d t+C_{p} \int_{t_{k}}^{t_{k+1}} \int_{\varepsilon_{p}}^{\varepsilon_{\varepsilon}} \varphi(\varepsilon, t) d \varepsilon d t\right)$

The novelty offered by this model compared to the existing ones is that it for the first time introduces the probability of preventive maintenance when the system condition reaches the value $\varepsilon_{\mathrm{p}}$ to $\varepsilon_{\mathrm{c}}$, in the observed interval. The aim of this is to give a more precise estimate of overall costs in the systems with condition based maintenance.

To find the optimal moment of diagnostics, two intervals will be considered: the interval between $t_{k-1}$ and $t_{k}$, and the interval between $t_{k}$ and $t_{k+1}$, so the overall costs in these two intervals are: 


$$
\begin{aligned}
C_{u} & =\left(\left(C_{i}(k+1)\left(1-\int_{t_{k-1}}^{t_{k}} f(t) d t\right)\right)+C_{c} \int_{t_{k-1}}^{t_{k}} f(t) d t+C_{o}\left(t_{k}-t\right) \int_{t_{k-1}}^{t_{k}} f(t) d t+C_{p} \int_{t_{k-1}}^{t_{k}} \int_{\varepsilon_{p}}^{\varepsilon_{c}} \varphi(\varepsilon, t) d \varepsilon d t\right)+ \\
& +\left(\left(C_{i}(k+1)\left(1-\int_{t_{k}}^{t_{k+1}} f(t) d t\right)\right)+C_{c} \int_{t_{k}}^{t_{k+1}} f(t) d t+C_{o}\left(t_{k+1}-t\right) \int_{t_{k}}^{t_{k+1}} f(t) d t+C_{p} \int_{t_{k}}^{t_{k+1}} \int_{\varepsilon_{p}}^{\varepsilon_{c}} \varphi(\varepsilon, t) d \varepsilon d t\right)
\end{aligned}
$$

The optimal time of diagnostics is calculated by differentiating the above expression with respect to $t_{k}$ and then making the obtained expression equal to zero. The expression is then equal to:

$$
\begin{aligned}
\frac{\partial C_{u}}{\partial t_{k}} & =\left(C_{i} \cdot k \cdot f\left(t_{k}\right)+C_{c} \cdot f\left(t_{k}\right)+C_{o}\left(\int_{t_{k-1}}^{t_{k}} f(t) d t-t_{k} \cdot f\left(t_{k}\right)-t_{k} \cdot f\left(t_{k}\right)\right)+C_{p} \int_{\varepsilon_{p}}^{\varepsilon_{c}} \varphi(\varepsilon, t) d \varepsilon\right)+ \\
& +\left(C_{i}(k+1) f\left(t_{k}\right)-C_{c} \cdot f\left(t_{k}\right)+C_{o}\left(-t_{k+1} \cdot f\left(t_{k}\right)+t_{k} \cdot f\left(t_{k}\right)\right)-C_{p} \int_{\varepsilon_{p}}^{\varepsilon_{c}} \varphi(\varepsilon, t) d \varepsilon\right) .
\end{aligned}
$$

After the expression is simplified and equated to zero, we obtain:

$C_{i} \cdot f\left(t_{k}\right)+C_{o}\left(F\left(t_{k}\right)-F\left(t_{k-1}\right)\right)-C_{o}\left(t_{k+1}-t_{k}\right) f\left(t_{k}\right)=0$

Finally, the optimal interval of carrying out system condition diagnostics is obtained in the form:

$t_{k+1}-t_{k}=\frac{F\left(t_{k}\right)-F\left(t_{k-1}\right)}{f\left(t_{k}\right)}+\frac{C_{i}}{C_{o}}$

\section{The Application of the Developed Model in Practice}

As has already been noted, there are various models of technical diagnostics, but their application is either complicated or they do not yield optimal results. Our aim was therefore not simply to develop another model, but to develop it and show its practical applicability. That is why we give considerable attention to this part of study, because its applicability is the test whether it is a new finding, or just another inapplicable model.

Since this mathematical model can best be tested on examples from practice, we observed the condition of machinery in a graphic industry in a specific time period, and where it was possible the whole lifetime of a machine was observed, from its procurement to the present. The reason for choosing graphic machines for observation was the fact that they belong to the process industry, where the stoppage in the process of printing, for example, of daily papers, cannot be compensated for, since the paper cannot be issued the following day. The machines used in our country are old, and their condition should be monitored, which is not the case.

On the basis of condition monitoring, it was concluded that machine failures are subject to the law of normal distribution.

$$
f(t)=\frac{1}{\sigma \sqrt{2 \pi}} e^{-\frac{(t-m)^{2}}{2 \sigma^{2}}}
$$

In general, the model developed is used to calculate the optimal moment of performing condition diagnostics by solving the nonlinear differential equation (equation of final differences), obtained 
by substituting the previous functions into the equation of optimal moment for performing diagnostic inspection.

$$
\begin{aligned}
t_{k+1}-t_{k}= & \frac{F\left(t_{k}\right)-F\left(t_{k-1}\right)}{f\left(t_{k}\right)}+\frac{C_{i}}{C_{o}} \\
t_{k+1}-t_{k}= & \frac{\frac{1}{\sigma \sqrt{2 \pi}} \int_{0}^{t_{k}} e^{-\frac{(t-m)^{2}}{2 \sigma^{2}}}-\frac{1}{\sigma \sqrt{2 \pi}} \int_{0}^{t_{k-1}} e^{-\frac{(t-m)^{2}}{2 \sigma^{2}}}}{\sigma \sqrt{2 \pi}} e^{-\frac{\left(t_{k}-m\right)^{2}}{2 \sigma^{2}}}+\frac{C_{i}}{C_{o}} \\
t_{k+1}-t_{k}= & \frac{\int_{0}^{t_{k}} e^{-\frac{(t-m)^{2}}{2 \sigma^{2}}}-\int_{0}^{t_{k-1}} e^{-\frac{(t-m)^{2}}{2 \sigma^{2}}}}{e^{-\frac{\left(t_{k}-m\right)^{2}}{2 \sigma^{2}}}+\frac{C_{i}}{C_{o}}, \text { where: }}
\end{aligned}
$$

$t_{k}-\mathrm{k}$-th optimal moment for performing diagnostics of the condition of a machine part, where

$\mathrm{k}=1,2,3, \ldots . . \mathrm{n}$,

$C_{i}$ - costs of diagnostic inspection of machine part

$C_{o}-$ costs of production losses due to a machine part failure,

$\sigma$ - standard deviation,

$m-$ mid period of time at work and

$t$ - time of failure.

Table 1 shows the failure times of the observed gears on the cylinders of a flexographic printing machine (Bjelica, 2005; Jardine, 1999).

Table 1: Times of gear failure [hour]

\begin{tabular}{|l|l|l|l|l|l|l|l|}
\hline 4530 & 12555 & 19956 & 24960 & 28541 & 33584 & 42154 & 54991 \\
\hline 6570 & 13456 & 20521 & 25047 & 29021 & 34564 & 44589 & 58574 \\
\hline 7250 & 15011 & 22035 & 25684 & 29874 & 35541 & 45025 & \\
\hline 9211 & 15298 & 23545 & 26581 & 31254 & 36732 & 46058 & \\
\hline 10521 & 16521 & 24547 & 26965 & 31599 & 37852 & 47052 & \\
\hline 11259 & 19021 & 24958 & 27548 & 32588 & 39584 & 50147 & \\
\hline
\end{tabular}

By analyzing these data and testing the hypothesis of normal distribution we obtained the mid time period at work value $m=27.792$ hours and standard deviation $\sigma=13.428$ (Dovich, 1990). By quantifying these values and the cost values $C_{i}=100 \mathrm{n.j}$ and $C_{o}=50 \mathrm{n} . \mathrm{j}$. in the above formula for determining the optimal moment of diagnostic inspection of the system condition, in this case gears in a graphic machine, in case of normal distribution, we obtain the optimal times of condition diagnostics in the calculations below.

Assuming the first time of diagnostics is close to the moment when the first failures start happening, i.e. when the first gear breaks down, for safety reasons we shall take that $t_{0}$ is 4.500 hours. The assumed diagnostic costs is $C_{i}=100$ monetary units per a procedure, and the cost of the failures due to untimely performed diagnostics procedures is $C_{0}=50$ monetary units per hour of work stoppage. Next, the complex formula is computed piecemeal, via: 


$$
\begin{aligned}
& \int_{0}^{t_{k}} e^{-\frac{(t-m)^{2}}{2 \sigma^{2}}} d t=\sqrt{\frac{\pi}{2}} \sigma\left(\operatorname{Erf}\left[\frac{m}{\sqrt{2} \sigma}\right]-\operatorname{Erf}\left[\frac{m-t_{k}}{\sqrt{2} \sigma}\right]\right) \\
& \int_{0}^{t_{k-1}} e^{-\frac{(t-m)^{2}}{2 \sigma^{2}}} d t=\sqrt{\frac{\pi}{2}} \sigma\left(\operatorname{Erf}\left[\frac{m}{\sqrt{2} \sigma}\right]-\operatorname{Erf}\left[\frac{m-t_{k-1}}{\sqrt{2} \sigma}\right]\right)
\end{aligned}
$$

The function Erf from the above expressions denotes Error function, which is the integral of the Gaussian function

$$
\operatorname{Erf}(\mathrm{z})=\frac{2}{\sqrt{\pi}} \int_{0}^{z} e^{-t^{2}} d t
$$

By substituting the above expressions into the initial equation for determining the optimal moment for carrying out technical diagnostics, we get the following expression:

$$
\begin{aligned}
& t_{k+1}=t_{k}+\frac{C_{i}}{C_{o}}+\frac{\sqrt{\frac{\pi}{2}} \sigma\left(-\operatorname{Erf}\left[\frac{m-t_{k}}{\sqrt{2} \sigma}\right]+\operatorname{Erf}\left[\frac{m-t_{k-1}}{\sqrt{2} \sigma}\right]\right)}{e^{-\frac{\left(t_{k}-m\right)^{2}}{2 \sigma^{2}}}} \\
& t_{k+1}=t_{k}+\frac{C_{i}}{C_{o}}+e^{\frac{\left(t_{k}-m\right)^{2}}{2 \sigma^{2}}} \sqrt{\frac{\pi}{2}} \sigma\left(\operatorname{Erf}\left[\frac{m-t_{k-1}}{\sqrt{2} \sigma}\right]-\operatorname{Erf}\left[\frac{m-t_{k}}{\sqrt{2} \sigma}\right]\right)
\end{aligned}
$$

By substituting the above expressions into the previous equation, and taking that $t_{k-1}=0$, we obtain:

$$
t_{k+1}=4502+6714 e^{\frac{418609}{278258}} \sqrt{2 \pi}\left(-\operatorname{Erf}\left[\frac{647}{373 \sqrt{2}}\right]+\operatorname{Erf}\left[\frac{386 \sqrt{2}}{373}\right]\right)
$$

By solving this expression we obtain the first optimal moment of carrying out technical diagnostics of the gear condition $t_{1}=7.860,63$ hours. So the first moment when it is necessary to perform condition diagnostics is determined by calculation, the value being 7.860 from the moment of setting the machine in motion or installing a new gear.

The next step required is to compute the time of the second diagnostic inspection, calculated using the same equation as the one used for finding $t_{1}$ :

$$
t_{k+1}=t_{k}+\frac{C_{i}}{C_{o}}+e^{\frac{\left(t_{k}-m\right)^{2}}{2 \sigma^{2}}} \sqrt{\frac{\pi}{2}} \sigma\left(\operatorname{Erf}\left[\frac{m-t_{k-1}}{\sqrt{2} \sigma}\right]-\operatorname{Erf}\left[\frac{m-t_{k}}{\sqrt{2} \sigma}\right]\right)
$$

In this equation the following variables are evaluated as $t_{k-1}=4.500, t_{k}=7.860, C_{i}=100, C_{0}=50$, $m=27.792, \sigma=13.428$, so that the equation becomes:

$$
t_{k+1}=7862+6714 e^{\frac{2758921}{2504322}} \sqrt{2 \pi}\left(-\operatorname{Erf}\left[\frac{1661}{1119 \sqrt{2}}\right]+\operatorname{Erf}\left[\frac{647}{373 \sqrt{2}}\right]\right)
$$


By solving it we get the value of the second time of diagnostic inspection $t_{2}=10.643$ hours. After that the third time of diagnostic control $t_{3}$ is to be determined, again on the basis of the equation:

$t_{k+1}=t_{k}+\frac{C_{i}}{C_{o}}+e^{\frac{\left(t_{k}-m\right)^{2}}{2 \sigma^{2}}} \sqrt{\frac{\pi}{2}} \sigma\left(\operatorname{Erf}\left[\frac{m-t_{k-1}}{\sqrt{2} \sigma}\right]-\operatorname{Erf}\left[\frac{m-t_{k}}{\sqrt{2} \sigma}\right]\right)$

in which the following values are quantified: $t_{k-1}=7.860, t_{k}=10.643, C_{i}=100, C_{0}=50, m=27.792$, $\sigma=13.428$. It is obvious how the values $t_{k-1}$ and $t_{k}$ are determined: the result of calculating the next diagnostics time is $t_{k}$, and the preceding calculation is $t_{k-1}$, except in the first case, where the first time is assumed as the approximate time of failure of the first gear. After evaluating all these quantities, the expression for $t_{3}$ becomes:

$t_{k+1}=10645+6714 e^{\frac{294088201}{360623368}} \sqrt{2 \pi}\left(-\operatorname{Erf}\left[\frac{17149}{13428 \sqrt{2}}\right]+\operatorname{Erf}\left[\frac{1661}{1119 \sqrt{2}}\right]\right)$

This equation gives the third time of performing diagnostics $t_{3}$, which is after 13.073 hours. By repeating the procedure we obtain the intervals for the performance of diagnostic inspections of the condition of the gears in graphic machines for flexographic print, presented in Table 2.

Table 2: Calculated optimal times for performing diagnostics and intervals of diagnostic controls of gears in machines for flexographic printing.

\begin{tabular}{|c|c|c|}
\hline $\begin{array}{l}\text { Moment of } \\
\text { performing } \\
\text { diagnostics }\end{array}$ & $\begin{array}{l}\text { Time of per- } \\
\text { forming diag- } \\
\text { nostics }\end{array}$ & $\begin{array}{l}\text { Diagnostics in- } \\
\text { terval }\end{array}$ \\
\hline $\mathrm{t}_{1}$ & 7860 & 3360 \\
\hline$t_{2}$ & 10643 & 2783 \\
\hline$t_{3}$ & 13073 & 2430 \\
\hline$t_{4}$ & 15267 & 2194 \\
\hline$t_{5}$ & 17296 & 2029 \\
\hline $\mathrm{t}_{6}$ & 19205 & 1909 \\
\hline$t_{7}$ & 21026 & 1821 \\
\hline$t_{8}$ & 22782 & 1756 \\
\hline$t_{9}$ & 24494 & 1712 \\
\hline$t_{10}$ & 26176 & 1682 \\
\hline$t_{11}$ & 27844 & 1668 \\
\hline$t_{12}$ & 29509 & 1665 \\
\hline$t_{13}$ & 31186 & 1677 \\
\hline$t_{14}$ & 32887 & 1701 \\
\hline$t_{15}$ & 34626 & 1739 \\
\hline$t_{16}$ & 36422 & 1796 \\
\hline$t_{17}$ & 38293 & 1871 \\
\hline$t_{18}$ & 40265 & 1972 \\
\hline$t_{19}$ & 42372 & 2107 \\
\hline$t_{20}$ & 44661 & 2289 \\
\hline$t_{21}$ & 47204 & 2543 \\
\hline$t_{22}$ & 50111 & 2907 \\
\hline$t_{23}$ & 53583 & 3472 \\
\hline$t_{24}$ & 58026 & 4443 \\
\hline
\end{tabular}


As can be seen in Table 2, the condition diagnostics procedures are the most frequent around the medial period of work, i.e. around 27.792 hours, and the intervals of diagnostic inspections are the shortest in this area. As this period is reached, the intervals of diagnostic inspections get shorter, and after the mid period of work, the intervals of diagnostic inspections become longer. This proves that the model is well founded, as it reflects normal distribution, as we had expected, and the results have proved the expectation. This is illustrated in the graph in Figure 1, where the intervals of the condition diagnostics and the times at which condition diagnostic procedures are performed can be seen. It also shows the number of condition diagnostic procedures necessary to carry out for the machine observed, or its component. The graph in Fig. 1 shows that the first diagnostic inspection is carried out at the time $t_{1}=7.860$ hours, from the moment of setting the machine in motion or the replacement of the given part, and that it takes 2.783 hours to the next inspection, so the next diagnostic inspection is due at the time $t_{2}=10.643$ hours from the moment of setting the machine in motion or the replacement of the given part. This is followed by further diagnostics moments, shown on the $x$-axis, and the bars on the $y$-axis indicate the value of intervals between two diagnostic inspections. As has been mentioned above, the interval between condition diagnostic procedures is reduced around the mid period of work, i.e. around 27.792 hours, where the diagnostics interval is reduced to approximately 1.700 hours. After that, the diagnostics interval increases, and the reason for that is the reduced number of monitored elements, as half of them have already failed. In the end the interval of diagnostic control increases and equals almost 5.000 hours, so the two final condition diagnostic procedures are carried out at the moments $\mathrm{t}=53.583$ and $\mathrm{t}=58.026$ hours from the moment of setting the machine in motion or the replacement of the part observed.

\section{Designing the Software Package for the Application of the Model}

The software was designed using the program Macromedia Flash Professional 8. The outlay of the package is given in the following images. The first image shows the way of setting the parameters for the graphic surrounding of the developed software, i.e. the outlay of objects, windows and other elements.

After the setup of the graphic environment, we proceeded with writing the program for the model developed. The program contains several pages. After programming we set to link the objects and activate the program.

Figure 3 shows that there are four windows in the completed software package: distribution type, data entering, table of obtained results and graphic representation of the results.

The other space is used for entering data. The value to be entered in the field 'Number of iterations' is the estimated number of condition diagnostics procedures, which is usually more than needed. If the number of diagnostics procedures required is lower, the excessive diagnostics will be eliminated by the program, which is visible in the results obtained. The unknown in this program is the value $t_{k+1}$, which is to be determined. This is the next time of diagnostics, or, in other words, the optimal moment of condition diagnostics calculated. The value $t_{k-l}$ is quantified as 0 , when the first moment of condition diagnostics is determined, because it is known that thus far no diagnostics has been carried out. Also, when determining the first time of condition diagnostics it is assumed that $t_{k}$ is equal as the moment of the first failure of he observed part. 


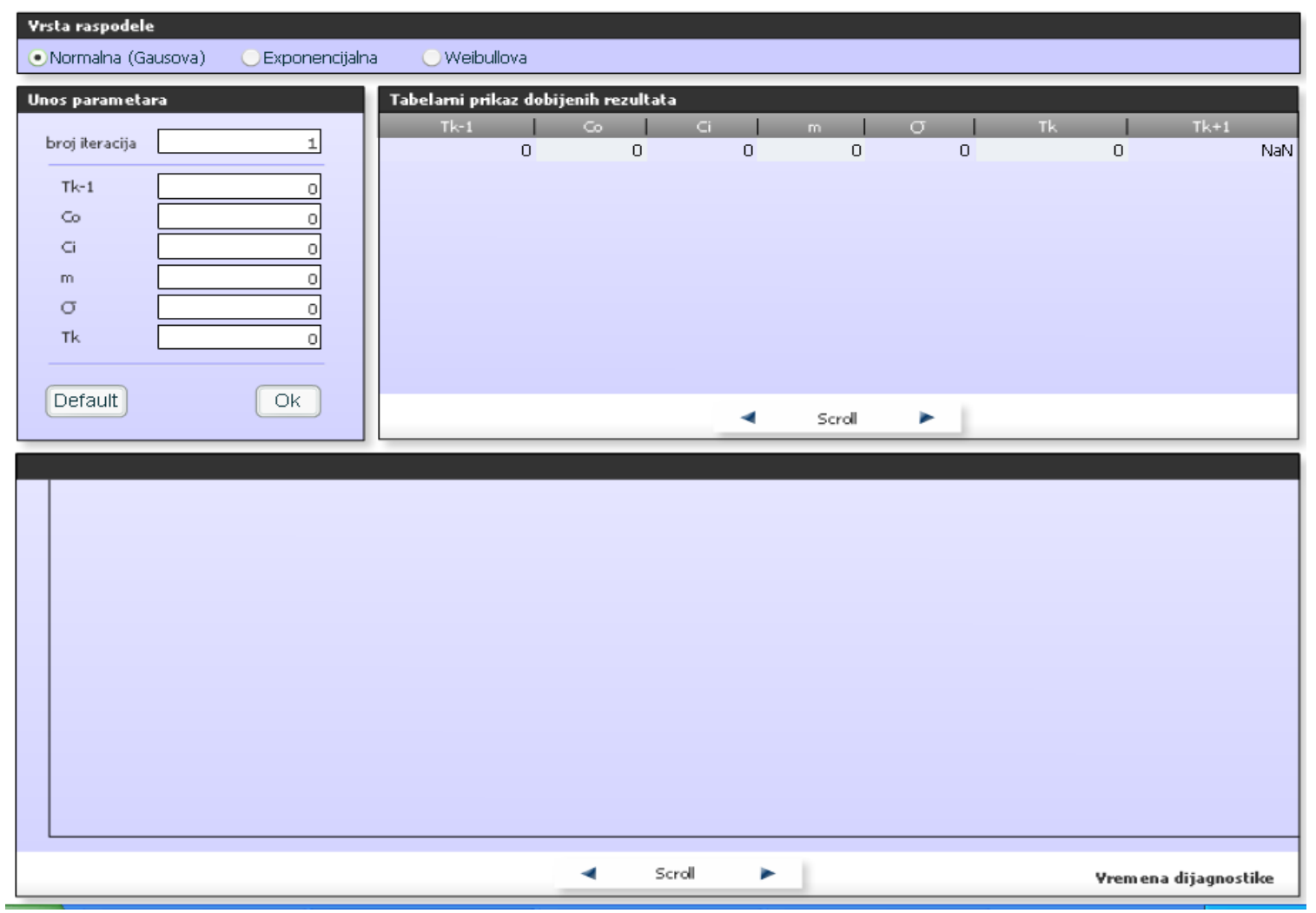

Figure 3: The outlay of the executable program of "Branka" software package for determining the optimal times of condition diagnostics of the system elements

\section{The application of the software package for determining the optimal moment of condition diagnostics}

For the example observed the application of the software package provides faster processing of the research results and obtaining optimal moments of technical diagnostics.

By processing these data and testing the hypothesis of normal distribution we obtained the input data for the program $t_{k-1}=0, t_{k}=4.500$ hours, $m=27.792$ and $\sigma=13.428$ hours, and the costs $C_{i}=100$ $n . j, C_{o}=50 n . j$.

After entering these values in the program and assuming the number of iterations is 30 , and then activating the program, in the window 'Table of results' we obtain the values of optimal moments of condition diagnostics in the column $t_{k+1}$, as shown in Figure 4. Also, the window with the graphic results in the same image shows the optimal diagnostics times for the gears observed. 

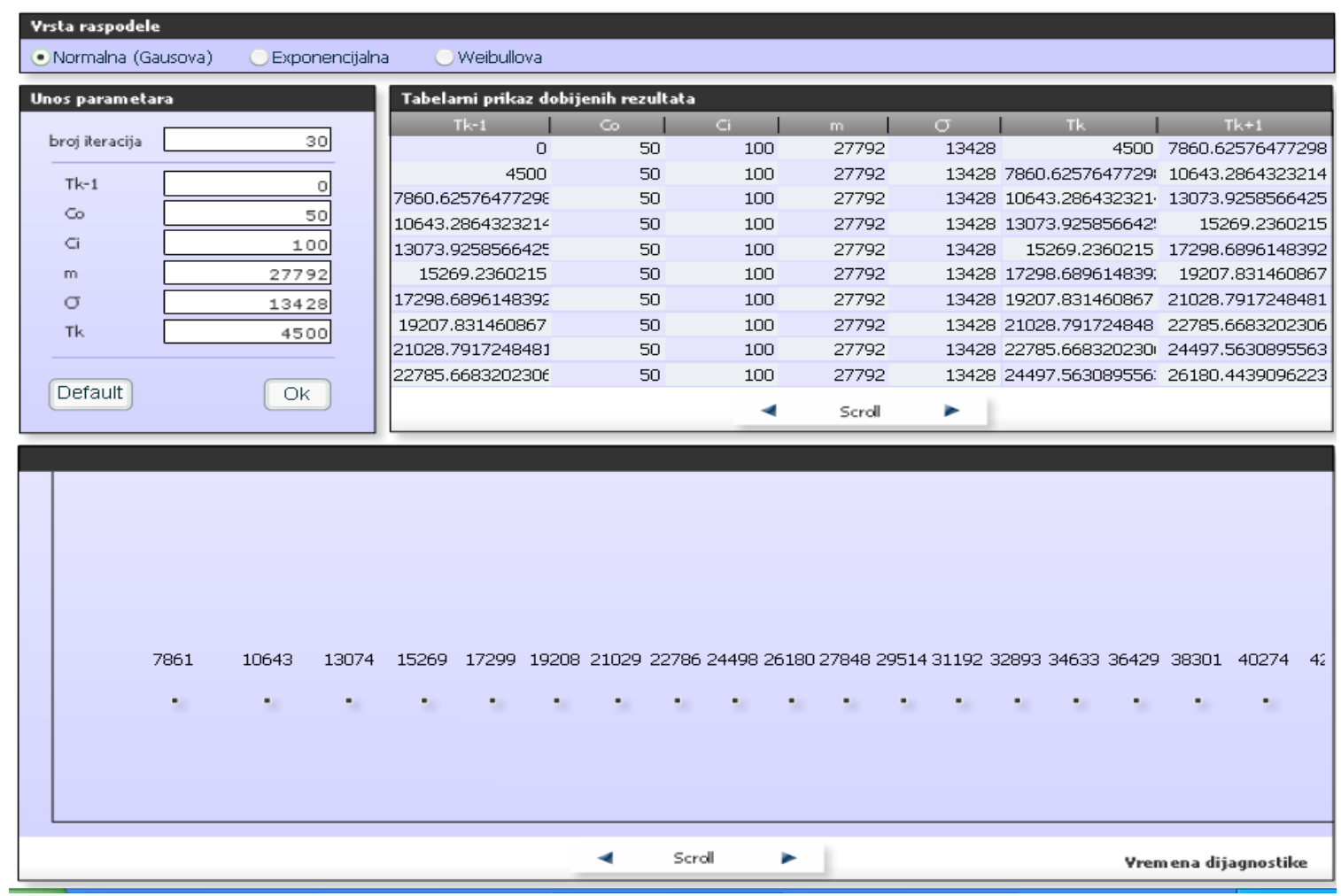

Figure 4: The application of the software package "Branka" for determining the optimal time of condition diagnostics for a gear

The complete condition diagnostic times calculated on the basis of the developed model $S A V$ TT05B are given in Table 3 . The same table shows the parameters used for calculating the optimal times of condition diagnostics $t_{k+1}$. Table 3 shows that the last two diagnostic times exceed the time limit, and that the last four diagnostics times are not applicable in practice because the last gear failed at 58.574 hours of work. Therefore, the estimated number of condition diagnostic procedures should be reduced by six, so 24 diagnostic procedures are required to inspect the gears in the time intervals obtained (column $t_{k+1}$ ).

What is essential in the process of testing the validity of the designed software package is the overlapping of results of the optimal diagnostic times in Table 3 with the occurrence of the gear failure in the machine observed. Therefore, the calculation of optimal condition diagnostics times of the observed element shows that the diagnostics procedures are the most frequent around the mid period of work before the failure, and the number of diagnostics procedures before and after that point have a decreasing tendency.

It is visible that condition diagnostics procedures are more frequent around the mid period of work, and that before and after that moment the number of procedures decreases as it parts further from the midpoint. We can thus conclude that the designed software package is appropriate for determining the optimal moment of condition diagnostics of the parts whose failures occur at normal distribution patterns, and with the application of the model SAV-TT05B for determining the optimal condition diagnostics time. 
Table 3: The optimal times for performing the condition diagnostics inspections of a gear obtained by the software package "Branka", on the basis of the developed model SAV-TTO5B

\begin{tabular}{|c|c|c|c|c|c|c|}
\hline Tk-1 & Co & $\mathrm{Ci}$ & m & $\sigma$ & Tk & $T k+1$ \\
\hline 0 & 50 & 100 & 27792 & 13428 & 4500 & 7860.62576477298 \\
\hline 4500 & 50 & 100 & 27792 & 13428 & 7860.6257647729 & 10643.2864323214 \\
\hline $7860.6257647729 \varepsilon$ & 50 & 100 & 27792 & 13428 & 10643.286432321 & 13073.9258566425 \\
\hline $10643.286432321^{<}$ & 50 & 100 & 27792 & 13428 & 13073.925856642 & 15269.2360215 \\
\hline 13073.9258566425 & 50 & 100 & 27792 & 13428 & 15269.2360215 & 17298.6896148392 \\
\hline 15269.2360215 & 50 & 100 & 27792 & 13428 & 17298.689614839: & 19207.831460867 \\
\hline $17298.689614839 \bar{c}$ & 50 & 100 & 27792 & 13428 & 19207.831460867 & 21028.7917248481 \\
\hline 19207.831460867 & 50 & 100 & 27792 & 13428 & 21028.791724848 & 22785.6683202306 \\
\hline 21028.7917248481 & 50 & 100 & 27792 & 13428 & 22785.668320230 & 24497.5630895563 \\
\hline $22785.668320230 €$ & 50 & 100 & 27792 & 13428 & 24497.563089556 & 26180.4439096223 \\
\hline $24497.563089556 \approx$ & 50 & 100 & 27792 & 13428 & 26180.443909622 & 27848.3860778787 \\
\hline $26180.443909622 \leftleftarrows$ & 50 & 100 & 27792 & 13428 & 27848.386077878 & 29514.4824196633 \\
\hline 27848.386077878 & 50 & 100 & 27792 & 13428 & 29514.482419663 & 31191.5918522043 \\
\hline $29514.482419663 \AA$ & 50 & 100 & 27792 & 13428 & 31191.591852204 & 32893.0437978325 \\
\hline $31191.591852204 \Xi$ & 50 & 100 & 27792 & 13428 & $32893.043797832 !$ & 34633.4009352883 \\
\hline 32893.043797832 & 50 & 100 & 27792 & 13428 & 34633.400935288: & 36429.3972117498 \\
\hline $34633.400935288 \AA$ & 50 & 100 & 27792 & 13428 & 36429.397211749 & 38301.2180494055 \\
\hline 36429.397211749ع & 50 & 100 & 27792 & 13428 & $38301.218049405 !$ & 40274.3992869785 \\
\hline 38301.218049405؟ & 50 & 100 & 27792 & 13428 & $40274.399286978 !$ & 42382.8535201528 \\
\hline 40274.399286978ᄃ & 50 & 100 & 27792 & 13428 & 42382.853520152 & 44674.0428253257 \\
\hline $42382.853520152 \varepsilon$ & 50 & 100 & 27792 & 13428 & 44674.042825325 & 47218.5280875683 \\
\hline 44674.042825325; & 50 & 100 & 27792 & 13428 & 47218.528087568 & 50129.3398885309 \\
\hline $47218.528087568:$ & 50 & 100 & 27792 & 13428 & 50129.339888530 & 53606.4413466582 \\
\hline $50129.339888530 \subseteq$ & 50 & 100 & 27792 & 13428 & 53606.441346658 & 58058.3077095646 \\
\hline $53606.441346658 \bar{c}$ & 50 & 100 & 27792 & 13428 & 58058.307709564 & 64538.669888719 \\
\hline $58058.307709564 \epsilon$ & 50 & 100 & 27792 & 13428 & 64538.669888719 & 77342.5065499108 \\
\hline 64538.669888719 & 50 & 100 & 27792 & 13428 & 77342.506549910 & 168527.524762024 \\
\hline $77342.506549910 \varepsilon$ & 50 & 100 & 27792 & 13428 & 168527.52476202 & $2.68811213752293 \mathrm{e}$ \\
\hline $168527.52476202^{2}$ & 50 & 100 & 27792 & 13428 & 2.6881121375229 & $\mathrm{NaN}$ \\
\hline $2.6881121375229=$ & 50 & 100 & 27792 & 13428 & NaN & $\mathrm{NaN}$ \\
\hline
\end{tabular}

\section{Conclusion}

The paper shows that the field of maintenance is very complex, but that it cannot be viewed solely as theory, but is fully realized in practice. In order to carry out maintenance, it is necessary to get a good command of the mathematic tools, because that is the only way in which one can successfully apply mathematical models in practice. The trends in maintenance are largely following the development of computer technologies and are increasingly using it. This results in the possibility of applying information technologies to develop and apply software packages for easier, faster and more precise maintenance. Education in the field of maintenance should go along the same lines. Obviously, it is possible to use modern technologies, above all computer technology, in the areas which are traditional, such as machine maintenance. In addition, the need for continuous education of teachers is also obvious. We can also conclude that it is possible to design software packages for the application of a model for determining the optimal time of condition diagnostics based on minimizing the total costs per time, such as $S A V-T T 05 B$. The software package developed provides optimal times of condition diagnostics for the observed parts. This software package has made the application of this model considerably easier, as the user does not have to deal with complex mathematical operations for determining the optimal diagnostics time, but can simply enter specific input data and enter them in the program. By simply pressing a key after entering the input data, the optimal diagnostic times for observed elements will be obtained, without much involvement in the model structure or software functioning. In this way, the appli- 
cation of the software package and the model developed would lead to a decrease in failures, and thus lower the costs of maintenance and contribute to the process of production. Course syllabi including these aspects introduce students into the practical work and application of the gained knowledge. It can be said that they gain knowledge through practice, dealing with real-life examples, which is a goal of every subject taught at vocational schools of higher education, so that, immediately after graduation, they can enter production process, in this case the process of maintenance.

\section{References}

Baldin, A., \& Furlaneto, L. (1980). Odrzavanje po stanju. OMO, Beograd.

Bengtsson, M. (2002) Condition based maintenance in technical systems. Department of Innovation. Design and Product Development Eskilstuna. Sweden.

Bjelica, M., Adamovic, Z., \& Savic, B. (2005). Dijagnostika stanja grafičkih mašina u D.O.O. MULTITEC i primena modela održavanja u cilju poboljšanja stanja. Projekat. Zrenjanin. Serbia

Dovich, R. A. (1990). Reliability statistics. Milwaukee. USA: ASQ Quality Press.

Gonzalez, J. (2006). Macromedia Flash Professional 8 Hands-On Training. Peachpit Press

Jardine, A. K. S., Joseph, T., \& Banjevic, D.(1999). Optimizing condition-based maintenance decisions for equipment subject to vibration monitoring. Journal of Quality in Maintenance Engineering, 5(3), 192202.

Powell, J. (2002). An introduction to integro-difference equations. Department of Mathematics and Statistics Utah State University. USA

Savić, B. (2005): Unifikacija i sistematizacija modela za utvrđivanje optimalnog perioda tehničke dijagnostike i njihova primena na grafičkim mašinama; doktorska disertacija Zrenjanin. god. Serbia.

\section{Biographies}

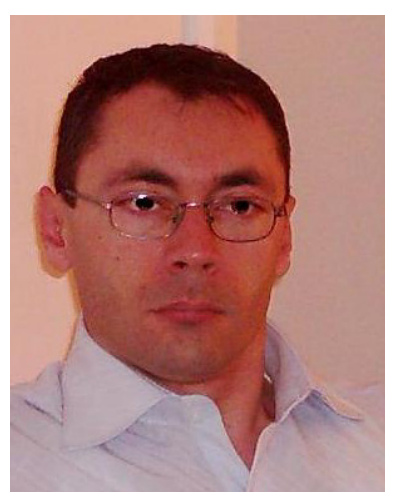

Dr Branko Savic was born on 03 March 1969th in Loznica, Serbia. He graduated in 1994. at the University of Novi Sad, Faculty of Technical Sciences, Department of Mechanical Engineering Department of manufacturing systems, robotics and automation. At the University he defended his magister thesis in the field of machine maintenance. He is employed at the School of Professional Higher Education Novi Sad, Serbia, as a teaching and research professor. His scientific areas of interest are graphics machines, reliability, from which he published, as an author or a coauthor, more than 55 scientific and professional papers at national and international conferences or in local journals. He participated in realization of several scientific research projects. He is also interested in software development and has taken part in several software development projects with commercial application. 


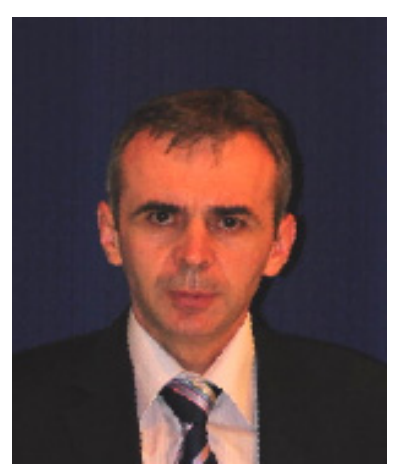

Mr. Bozo Ilic was born on 07 January 1966 in Trnovica, Bosnia and Herzegovina. He graduated in 1991. at the University of Tuzla, Faculty of Electrical Engineering, Department of Power Supply. At the Faculty of Technology Zvornik he defended his magister thesis in the field of technology science. He is employed at the Secondary School in Zvornik, Bosnia and Herzegovina, as a teacher. His scientific areas of interestare electrical wiring, stray currents and distance learning, from which he published, as an author or a coauthor, more than 10 scientific and professional papers at national and international conferences. He is also interested in software development. 